Full-text Available Online at www.bioline.org.br/ja
J. Appl. Sci. Environ. Mgt. March, 2006

Vol. 10 (1) $79-82$

\title{
Spectrophotometric Determination of Nitrate in Vegetables Using Phenol
}

\author{
"GAYA, U I; ALIMI, S \\ Department of Chemistry, Bayero University, P.M.B 3011, Kano, Nigeria \\ *Corresponding Author. E-mail: umargaya2000@yahoo.com
}

\begin{abstract}
A rapid and sensitive spectrophotometric method for the determination of nitrate in vegetables is described. The method is based on the measurement of the absorbance of yellow sodium nitrophenoxide formed via the reaction of phenol with the vegetable-based nitrate in presence of sulphuric acid. The analytical concentration of the acid has marked effect on the nitrate determined. The colour development was rapid and remained stable overnight. Analysis of six vegetable samples containing nitrate gave satisfactory mean recoveries of 76 to $123 \%$ in 18 determinations. The proposed method is reproducible and sensitive to lower level concentrations. @JASEM.
\end{abstract}

The high concentration of nitrogen in soil may lead to the high nitrate levels in edible vegetables and toxic levels of nitrite may be produced by microbial activity in the gastrointestinal tract of the consumer of such vegetables (Tanaka et al., 1982). Nitrate containing vegetables are potential causes of methemoglobinemia, a disease which may occur in children older than 6 month (Sanchez-Echaniz et al., 2001). Since nitrate-nitrogen is lost during digestion (Rowell, 1994), the determination of nitrate as nitrate-nitrogen via digestion becomes difficult. Pfeiffer and Smith (1975) determined nitrate in baby food using ion selective electrode which showed a good correlation with the AOAC xylenol method. Some of the methods employed are based on the nitration of bi-substituted phenol such as 2,4-xylenol, 3,4-xylenol and 2,6-xylenol (Tanaka et al., 1982). Due to the involvement of distillation stage the 2,4xylenol method is time consuming (Tanaka et al., 1982) and therefore unsuitable for routine food analysis. The 2,4-xylenol method was modified by
Toyoda et al. (1978) and a gas-liquid chromatographic method was developed. Basset et al. (1978) reported a titrimetric method for the nitrate determination which could be erroneous if applied to vegetables. Tanaka et al. (1982) reported a sensitive and direct spectrophotometric method for the determination of nitrate in vegetables using 2-secbutyl phenol. The basis for the method is that 2-secbutylphenol reacts quantitatively with nitrate in acidic solution. Beijaars et al. (1994) reported a determination of nitrate in vegetables by continuous flow procedure and subsequent reaction of the nitrate extracted with sulfanilamide and N-1naphthylethylenediamine to form a reddish-purple azo dye which was measured colorimetrically at $530 \mathrm{~nm}$. This research aimed at developing a method for the determination of nitrate in vegetable products by using phenol as the active reagent. The principle is based on the nitration of phenol and the formation of the corresponding sodium salt. The elementary processes involved are

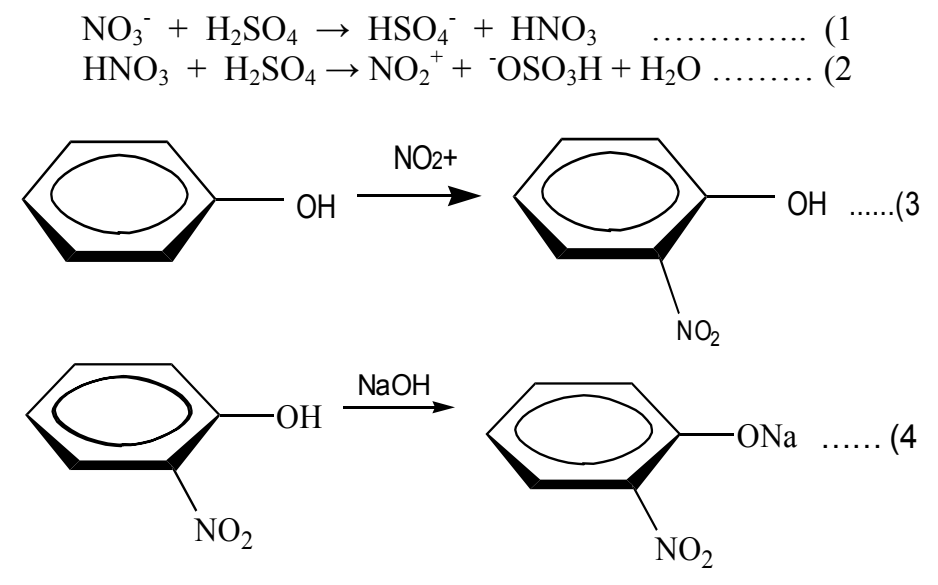

Ultimately, $1 \mathrm{~mol}$ of sodium nitrophenoxide is produced from $1 \mathrm{~mol}$ of nitrate-nitrogen. Since sodium nitrophenoxide absorbs ultraviolet light it

provides a basis for the determination of nitrate as nitrate-nitrogen. The reaction is quantitative and analogous to that reported by Tanaka et al. (1982). 


\section{MATERIALS AND METHODS}

Unicam UV 1 uv-visible spectrophotometer v1.30 was used for analysis. Fresh vegetable samples were obtained from Dorayi ward, forming part of Kumbotso Local Government, Kano, Nigeria. All reagents used were of analytical-reagent grade. The vegetable sample was chopped and ground in a porcelain mortar till homogeneous slurry was formed. $10 \mathrm{~g}$ of the slurry was taken into a $250 \mathrm{~cm}^{3}$ beaker by washing with $70 \mathrm{~cm}^{3}$ distilled water and $2.5 \mathrm{ml}$ of $4 \% \mathrm{NaOH}$ was added. The content of the beaker was warmed at $80^{\circ} \mathrm{C}$ for $25 \mathrm{~min}$ with occasional shaking. The resulting solution was filtered through a fluted filter paper into $100 \mathrm{~cm}^{3}$ volumetric flask and made up to the mark. An aliquot of $4 \mathrm{~cm}^{3}$ was taken into a test tube cooled in ice. $1 \mathrm{~cm}^{3}$ of $5 \%$ $\mathrm{Ag}_{2} \mathrm{SO}_{4}$ solution was added followed by subsequent addition of $7 \mathrm{~cm}^{3}$ of $98 \% \mathrm{H}_{2} \mathrm{SO}_{4}$ and $0.1 \mathrm{~cm}^{3}$ of $5 \%$ phenol solution. The solution was allowed to stand for $20 \mathrm{~min}$ while shaking occasionally. The resulting mixture was extracted in $50 \mathrm{~cm}^{3}$ separating funnel by adding toluene and shaking for 5 to $10 \mathrm{~min}$. The lower aqueous layer was discarded. The organic phase was washed twice with $10 \mathrm{ml}$ of distilled water by shaking for $2 \mathrm{~min}$ and each time discarding the aqueous phase. The organic phase was extracted again by shaking for 1 min with $10 \mathrm{~cm}^{3}$ of $10 \% \mathrm{Na}_{2} \mathrm{CO}_{3}$ solution and collected in a test tube. Absorbance was read at $407 \mathrm{~nm}$. Since $4 \mathrm{~cm}^{3}$ of the $100 \mathrm{~cm}^{3}$ filtrate was used for analysis. The amount of nitrate $(\mu \mathrm{g} / \mathrm{g})$ in the vegetable was calculated by the formula

Nitrate $=\frac{\mathrm{C} \times 100}{\mathrm{~W}_{\mathrm{s}} \times 4}$

where $\mathrm{C}=$ Concentration of nitrate in the sample as from calibration graph $\left(\mu \mathrm{g} \mathrm{cm}^{-3}\right)($ Fig $1 \mathrm{a}) ; \mathrm{W}_{\mathrm{s}}=$ Weight of the slurry used $(\mathrm{g})$.

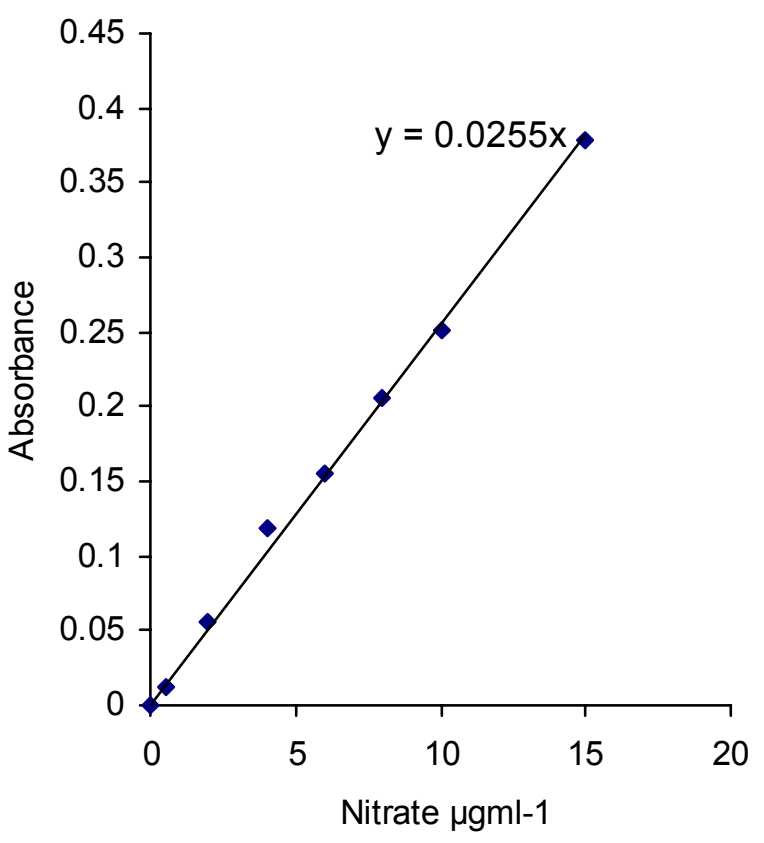

Fig 1a. Nitrate calibration curve
Aliquots of standard nitratenitrogen solutions were taken through the procedure at the same time as the samples and calibration curve was prepared. A recovery test was attempted intraday to ensure validity of the method. In the filtration step above, $5 \mathrm{~cm}^{3}$ of $50 \mu \mathrm{gcm}^{-3}$ solution was added to the filtrate and made up to $100 \mathrm{~cm}^{3}$ with distilled water. The procedure was then applied. To investigate the effect of reaction time $4 \mathrm{~cm}^{3}$ of standard nitrate solution at level of $5 \mu \mathrm{gcm}^{-3}$ was used for the nitrate determination and absorbance of the coloured product was read after time intervals of $2,5,10,15,20$ and 25 minutes. The concentration of $\mathrm{H}_{2} \mathrm{SO}_{4}$ was varied to determine the suitable amounts required for effective nitration in the procedure. $4 \mathrm{~cm}^{3}$ aliquots of $10 \mu \mathrm{gcm}^{-3}$ standard nitrate-nitrogen solutions were added to five different test tubes and carried through the procedure with addition of $0,40,60,80$ and $98 \% \mathrm{v} / \mathrm{v}$ sulphuric acid solutions respectively. A graph of absorbance against $\%$ acid was plotted. The effect of increasing amounts of phenol and $\mathrm{Na}_{2} \mathrm{CO}_{3}$ were studied at levels of $10 \mu \mathrm{gcm}^{-3}$. For each of the reagents concentrations of $3,5,8,10$ and $15 \%$ were used in the procedure and a graph of absorbance against concentration was plotted in each case. The effect of the use of a different solvent for extraction was investigated by carrying samples of standard nitrate solution at level of $10 \mu \mathrm{gcm}^{-3}$ through the procedure and adding $10 \mathrm{ml}$ of benzene instead of toluene. The process was repeated with xylene, ethanol and $\mathrm{CCl}_{4}$ and observations were made.

\section{RESULTS AND DISCUSSION}

The formation of sodium salt of nitrophenol through the reaction of vegetable- based nitrate with phenol was quantitative and provided a fundamental line for the 
determination of nitrate. The reaction was confirmed by the procedures of Boxer (1997) where upon addition of drops of concentrated $\mathrm{HCl}$ the yellow colour of the sodium phenoxide was discharged. The resulting alkaline extract was found to absorb at wavelength maximum of $407 \mathrm{~nm}$ when measured with spectrophotometer. There was rapid colour development and no measurable change in absorbance for 25 minutes of standing after full colour development (Fig 1).

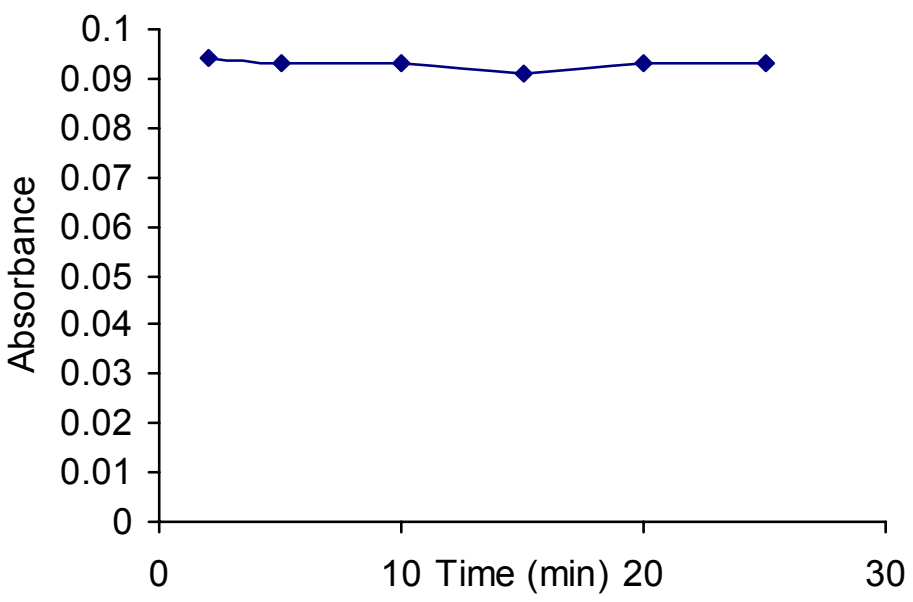

Fig 1 Effect of reaction time for nitration

The colour remained overnight. This is an indication of the stability of the sodium nitrophenoxide. Evidently, the time of reaction does not have modifying effect in the analysis. Prior to the choice of toluene, other solvents were tested as extractants but were found to be unsuitable. Benzene, xylene, ethanol and $\mathrm{CCl}_{4}$ formed emulsion during the extraction process. Further, benzene extract appeared to be a dirty brown coagulation. Tanaka et al. (1982) found toluene suitable for extraction of phenoxide in the nitrate determination with 2-sec-butyl phenol. Toyoda et al. (1978) used hexane to extract 6-nitro-2,4-xylenol in a modified 2,4-xylenol method for the determination of nitrate.

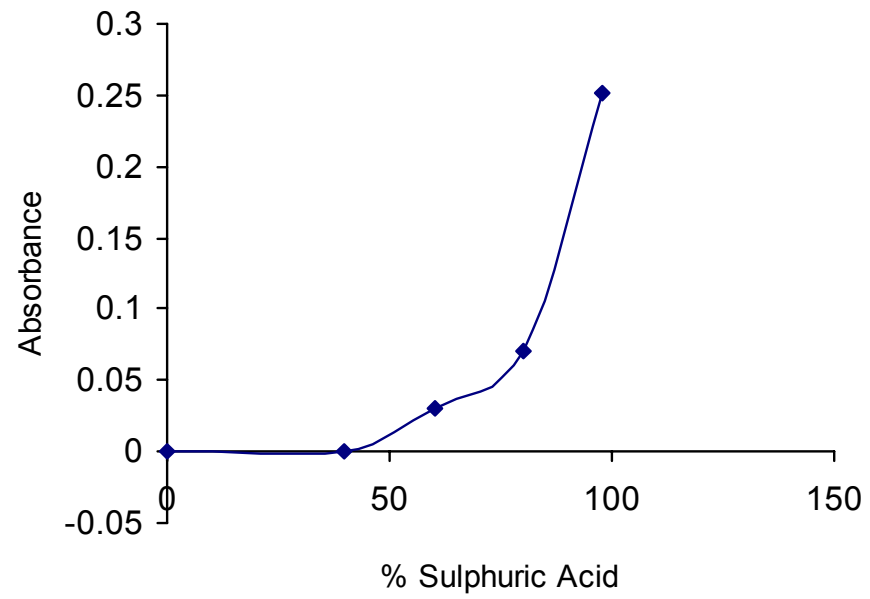

Fig 2 Effect of sulphuric acid concentration on the nitrate determination
Satisfactory recoveries of 76 to $123 \%$ were obtained when the sample of spinach, lettuce, water leaf, potato, tomato juice and onion were spiked with nitrate at level of $50 \mu \mathrm{gcm}^{-3}$ (Table 1). Pfeiffer and Smith (1975) used the similar nitrate addition method to ensure correct electrode response during nitrate determination. BCS (1983) had recoveries of up to 80 to $114 \%$ of the nitrate added to six different vegetables, cheeses and meat products at levels of 10 to $30 \mu \mathrm{gcm}^{-}$ ${ }^{3}$. Toyoda et al.(1978) reported recoveries of 83 to $100 \%$ from several foods. Sulphuric acid has a marked effect on the nitration of phenol and hence the determination of nitrate. Fig 2 indicated that with dilute sulphuric acid solution the nitration was not effective.

The graph indicated sharp rise in the amount of nitrate detected as the concentration of the acid is increased. Nitrate was not detected when sulphuric acid concentration was below $40 \%$. The use of $98 \%$ $\mathrm{H}_{2} \mathrm{SO}_{4}$ was therefore recommended for the procedure. Nearly equal amounts of nitrate were determined successfully in aliquots of standard nitrate-nitrogen solutions at a level of $10 \mu \mathrm{gcm}^{-3}$ by using different phenol concentrations of $3,5,8,10$ and $15 \%$ (Fig 3). In the proposed procedure $5 \%$ phenol was recommended. There was no significant difference in the amount of nitrate determined with $\mathrm{Na}_{2} \mathrm{CO}_{3}$ concentration of $3,5,8,10$ and $15 \%$. Therefore, the variation of the concentration of $\mathrm{Na}_{2} \mathrm{CO}_{3}$ solution in the procedure does not affect the nitration reaction (Fig 4). However, observation showed that at concentrations higher than $15 \%$ the solution became saturated at room temperature. For this reason, $10 \%$ $\mathrm{Na}_{2} \mathrm{CO}_{3}$ was recommended. Interfering chlorides were precipitated by the addition of $1 \mathrm{~cm}^{3}$ of $5 \% \mathrm{Ag}_{2} \mathrm{SO}_{4}$ solution. 
Table 1 Recoveries of nitrate added as $\mathrm{KNO}_{3}$ to certain vegetable products at level of $50 \mu \mathrm{gcm}^{-3}$

\begin{tabular}{lccc}
\hline Sample & $\begin{array}{c}\text { Nitrate } \\
\text { Found }(\mu \mathrm{g})\end{array}$ & $\begin{array}{c}\text { No of } \\
\text { Determinations }\end{array}$ & $\begin{array}{c}\text { Mean } \\
\text { Recovery }(\%)\end{array}$ \\
\hline Spinach & $308 \pm 14$ & 3 & 123 \\
$\begin{array}{l}\text { Lettuce } \\
\text { Water }\end{array}$ & $296 \pm 9$ & 3 & 118 \\
$\begin{array}{l}\text { Leaf } \\
\text { Potato }\end{array}$ & $236 \pm 8$ & 3 & 101 \\
$\begin{array}{l}\text { Tomato } \\
\text { Juice }\end{array}$ & $185 \pm 6$ & 3 & 94 \\
Onion & $189 \pm 6$ & 3 & 74 \\
\hline
\end{tabular}

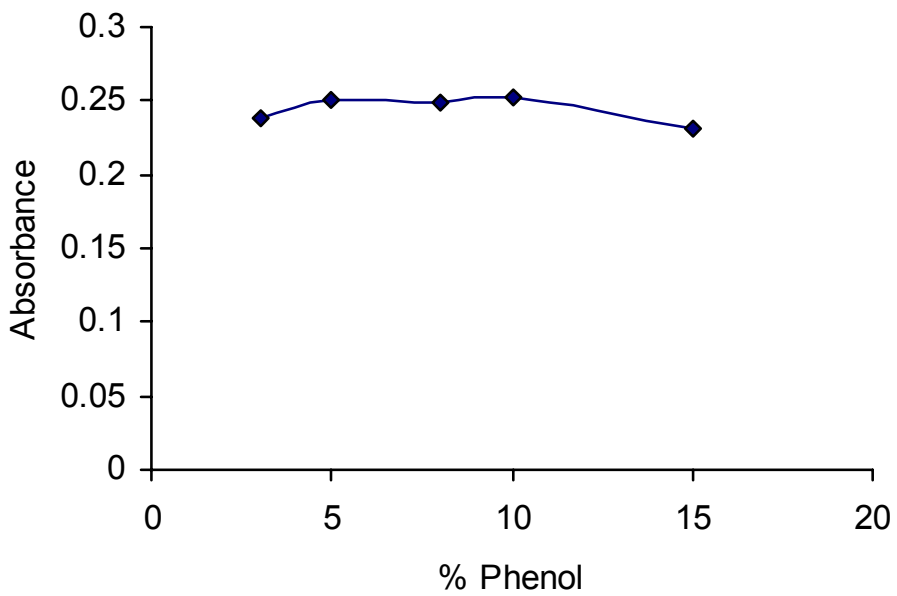

Fig 3. Influence of increasing phenol concentration on the absorbance of nitrate

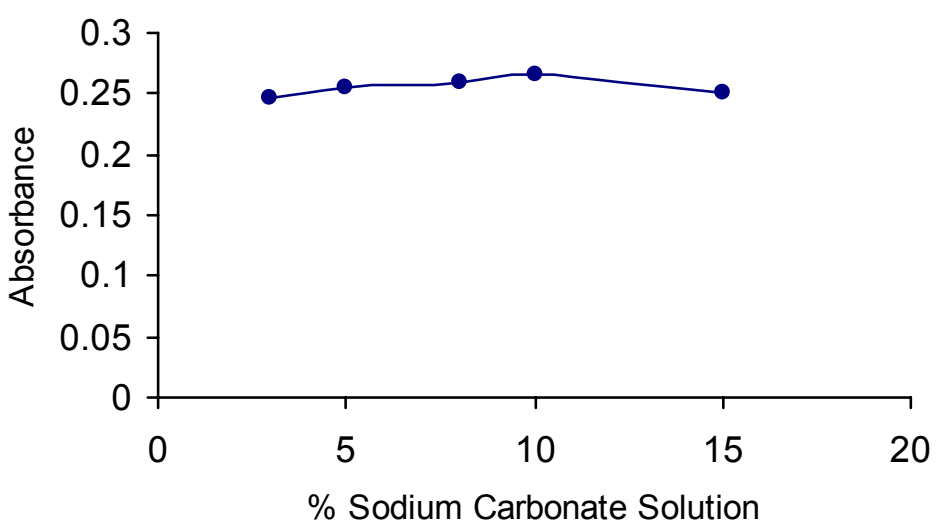

Fig 4. Influence of $\mathrm{Na}_{2} \mathrm{CO}_{3}$ concentration on the nitrate determined

Conclusion: The determination of nitrate using the developed method is rapid and precise. The nitrate recovery test in Table 1 indicated that the method is specific for nitrate. The remarkable constancy of the absorbance of the coloured solution with time (Fig 1) indicated suitability for analytical use. The reagents involved are common, cheap and suitable for routine analysis.

Acknowledgement: The authors acknowledge the contribution of Musa Beli of Central Laboratory Complex, Bayero University Kano.

\section{REFERENCES}

Bassett, J; Denney, RC; Jeffery, GH; Mendham, J (1978) Vogel's Textbook of Quantitative Inorganic Analysis, ELBS and Longman, London, pp686

BCS (1983) Colorimetric Determination of Nitrate and Nitrite in Foods, Laboratory Procedure, LPFC-126, Health Protection Branch Laboratories, Bureau of Chemical Safety, Ottawa, Canada

Beijaars, PR; van Dijk, R; van der Horst, GM (1994) Determination of Nitrate in Vegetables by Continuous Flow: Interlaboratory Study, J. Assoc. Off. Anal. Chem. 77(6):1522-9

Boxer, RJ (1997) Essentials of Organic Chemistry. WCB / McGraw-Hill Companies, United States of America, pp301-306

Pfeiffer, SL and Smith, J (1975) Nitrate Determination in Baby Food Using the Nitrate Ion Selective Electrode, J. Assoc. Off. Anal. Chem. 58(5):915-9

Rowell, DL (1994) Soil Science; Methods and Applications. Longman Singapore Publishers (Pte) Ltd, Singapore, pp55

Sanchez-Echaniz, J; BenitoFernández, J; Mintegui-Raso, S (2001) Methomoglobinemia 
and Consumption of Vegetables in Infants, Pediatrics, 107(5):1024-1028

Tanaka, A; Nose, N; Iwasaki, H (1982) Spectrophotometric Determination of Nitrate in Vegetable Products Using 2-secButylphenol, Analyst, 107:190-194
Toyoda, M; Susuki, H; Ito, Y; Iwaida, M (1978) Gas-Liquid Chromatographic

Determination of Nitrate and Nitrite in Cheese, Ham, Fish Sausage, Cod roes and Salmon roes, J. Assoc. Off. Anal. Chem. 61(3):508-12 